\title{
Perencanaan Strategi Pengembangan Usaha Pada PT. Dok dan Perkapalan Surabaya
}

\author{
Niken Saraswati, Imam Rochani, dan Yeyes Mulyadi \\ Departemen Teknik Kelautan, Fakultas Teknologi Kelautan, Institut Teknologi Sepuluh Nopember \\ (ITS) \\ e-mail:imamr@oe.its.ac.id
}

\begin{abstract}
Abstrak-Sangatlah penting sebuah perusahaan untuk mengetahui peluang apa saja yang dapat dikembangkan dan ancaman apa saja yang harus dihindari. Selain itu, sebuah perusahaan juga harus dapat memahami kekuatan sekaligus kelemahan yang dimiliki. Tujuan dilakukannya penelitian ini adalah untuk dapat menentukan strategi pengembangan usaha yang tepat. Sedangkan dalam proses mendapatkan variasi strategi pengembangan usaha, akan ditentukan juga kekuatan, kelemahan, peluang, dan ancaman dari faktor eksternal maupun internal perusahaan. Untuk mendapatkan faktor kekuatan dan kelemahan maka dilakukan dengan metode Business Model Canvas (BMC), sedangkan untuk mengetahui faktor peluang dan ancaman untuk perusahaan dilakukan dengan metode $4 C$ Diamond Analysis. Selanjutnya dengan menggunakan analisa External Factor Analysis summary (EFAS) dan Internal Factor Analysis summary (IFAS), didapatkan posisi perusahaan. Dengan menggunakan TOWS matriks nantinya akan didapat variasi jenis strategi. Lalu dengan metode Analytical Hierarchy Process (AHP) akan dapat ditentukan strategi mana yang paling sesuai dengan keadaan perusahaan. Sesuai hasil perhitungan AHP, maka strategi yang dapat digunakan adalah meningkatkan kinerja perusahaan agar terus dapat bersaing dengan bobot prioritas 0,17 .
\end{abstract}

Kata Kunci-AHP, Analisis Tows, Galangan, Manajemen Strategi.

\section{PENDAHULUAN}

I NDUSTRI galangan kapal nasional dianggap sebagai salah satu sektor strategis dalam pembangunan Indonesia, sehingga pengembangannya perlu terus dipacu. Sebagai industri yang berkembang secara global dan dipengaruhi secara makro karenanya pemerintah memiliki peran yang penting untuk ikut andil dalam mengembangkan agar memiliki daya saing tinggi [1]. Namun kondisi saat ini, perkembangan industri galangan nasional masih sangat lambat bahkan beberapa mengalami stagnasi. Meskipun pemerintah telah memberikan insentif seperti bea masuk pembelian komponen dan tunjangan pajak dibayar oleh pemerintah, industri galangan kapal akan tetap tidak akan mencapai target dalam waktu dekat dan belum efektif.

Kementrian Perhubungan sempat mengadakan tender pembangunan 150 buah kapal pada tahun 2015, namun tidak berlanjut hingga tahun 2017. Terdapat pula program dari Badan Perencanaan Pembangunan Nasional yang akan membangun kapal navigasi, tapi juga dibatalkan. Rujukan [2] menjelaskan, saat ini galangan swasta sedang banyak memegang proyek pembangunan kapal pemerintah, hal itu tidak bisa menjadi jaminan untuk pertumbuhan indutsri galangan dalam negeri.

Industri kapal dalam negeri masih memiliki potensi untuk terus berkembang sejak ditetapkannya kewajiban lembaga negara dan BUMN untuk membangun kapal di perusahaan milik negara. Selain itu, dengan adanya program sinergi BUMN juga diharapkan dapat membangun industri galangan kapal dalam negeri [3].

PT Dok dan Perkapalan Surabaya merupakan salah satu badan usaha milik Negara. DPS sebutan lain dari PT Dok dan Perkapalan Surabaya didirikan pada 1910 dengan nama NV Drogdok Maatschappij. Sejak 1961 DPS tercatat telah membangun lebih dari 600 unit kapal. Laba yang diperoleh DPS sendiri meningkat dari tahun 2014 ke 2015 sesuai data yang diungkapkan oleh Riry selaku direktur utama kala itu [4]. Di tahun 2017 ini, DPS mendapatkan pesanan tiga unit kapal, terdiri dari dua unit tug boat dan satu unit kapal tanker 6500 DWT [5]. Di sisi lain, menurut catatan dari Deputi Bidang Usaha Pertambangan, Industri Strategis dan Media Kementrian BUMN, terdapat perusahaan negara yang masih mengalami kerugian, salah satunya adalah DPS [6].

Terdapat berbagai macam faktor seperti yang telah disebutkan di atas memiliki berbagai jenis dampak pula terhadap perkembangan usaha perusahaan. Untuk itulah setiap perusahaan perlu dapat mengenali kekuatan dan kelemahan yang dimiliki dalam upaya untuk dapat terus berkembang. Memanfaatkan setiap peluang juga menimalkan setiap ancaman yang ada juga cara untuk perusahaan lebih mengetahui lagi potensi yang ada untuk terus berkembang. Perusahaan dituntut untuk terus berinovasi agar dapat menentukan strategi baru dengan membuat business plan dengan kondisi terkini.

Dalam arena bisnis, pengelompokan dalam internal dan eksternal adalah titik awal untuk perencanaan bisnis [7]. Analisis TOWS (threat, opportunity, weakness, strength) merupakan suatu alat yang popular untuk merencanakan sebuah strategi, dimana alat ini dapat mengidentifikasi faktor eksternal (peluang dan ancaman) dan internal (kekuatan dan kelemahan). Dari identifikasi faktor - faktor tersebut diharapkan dapat menghasilkan strategi yang efektif dengan cara mengambil keuntungan dari kekuatan, menghilangkan kelemahan, mengeskpoitasi peluang, dan melawan ancaman [8]. Kekuatan posisi produk di pasar sangat berpengaruh terhadap umur kelangsungan hidup dari sebuah produk di pasar. Dengan demikian dengan TOWS ini dapat diketahui hal- 
hal yang dapat dipertimbangkan untuk memperkuat posisi produk di pasar [9].

Metode kombinasi antara TOWS dan Analytical Hierarcy Process (AHP) telah diaplikasikan pada beberapa kasus seperti pemilihan rencana strategi pada suatu perusahaan galangan. Metode AHP digunakan untuk menentukan bobot pada masing - masing faktor yang telah dihasilkan oleh analisa TOWS. Metode AHP merupakan salah satu metode yang dapat menterjemahkan karakter kualitatif faktor - faktor TOWS menjadi karakter yang kauntitatif.

\section{URAIAN PENELITIAN}

\section{A. Pengumpulan Data}

Pengumpulan data ini berguna untuk mendukung dari hipotesa penelitian. Data yang digunakan adalah yang berhubungan dengan evaluasi penelitian. Data ini berfungsi sebagai bahan analisis kondisi terkini dari perusahaan. Terdapat data primer yang merupakan hasil dari wawancara juga kuisioner dan data sekunder yang merupakan hasil dari studi literatur.

\section{B. Identifikasi Data}

Mengidentifikasi data yang telah didapat. Kemudian data ini diidentifikasi untuk dibedakan menjadi faktor eksternal atau menjadi faktor internal.

\section{Business Model Canvas (BMC)}

Business model canvas ditampilkan dalam sebuah kanvas yang terdiri dari 9 elemen yang digambarkan pada 9 kotak. Sembilan elemen tersebut terdiri dari key partners, key activities, key resources, cost structure, value propositions, customer relationships, channels, customer segments dan revenue streams.

\section{4C Diamond Analysis}

$4 C$ Diamond analysis merupakan prasyarat sebelum melakukan analisis TOWS. 4C Diamond sendiri terdiri dari empat faktor yang saling terkait, yaitu : Perubahan (change), Pesaing (competitor), Pelanggan (customer), dan Perusahaan (company).

\section{E. Penentuan Matriks IFAS dan EFAS}

Matrik IFAS \& EFAS didapat melalui pengolahan faktor internal dan eksternal yang kemudian akan dihasilkan angka untuk menetapkan tema strategi yang akan digunakan.

\section{F. Evaluasi Faktor Internal dan Eksternal}

Evaluasi faktor internal ini bertujuan untuk menilai serta mengoreksi hasil dari perhitungan dan juga hasil dari analisa yang telah dilakukan terhadap bobot penilaian dan rating yang diberikan. Evaluasi ini akan dilakukan dengan bantuan expert judgment atau pakar yang berkompeten. Evaluasi faktor internal ini bertujuan untuk menilai serta mengoreksi hasil dari perhitungan dan juga hasil dari analisa yang telah dilakukan terhadap bobot penilaian dan rating yang diberikan. Evaluasi ini akan dilakukan dengan bantuan expert judgment atau pakar yang berkompeten.

\section{G. Matriks IE}

Matriks ini menggunakan parameter kekuatan internal dan pengaruh eksternal yang dihadapi. Dimana, nantinya dapat dilihat dari hasil pembobotan kondisi perusahaan atau organisasi saat ini.

\section{H. Matriks TOWS}

Berdasarkan Faktor eksternal dan Internal yang telah didapatkan sebelumnya maka disusunlah matriks TOWS. Sehingga nantinya didapatkan rekomendasi strategi alternatif.

\section{Analytical Hierarchy Process}

Mencari strategi mana yang memiliki bobot nilai tertinggi. Sehingga nantinya didapatkan strategi yang paling tepat dan efektif untuk dilakukan oleh perusahaan.

\section{PEMBAHASAN DAN HASIL}

\section{A. Analisa Kondisi Eksternal}

Kondisi eksternal sebuah perusahaan atau organisasi dapat dianalisa dengan menggunakan berbagai macam metode. Salah satu metode yang dapat digunakan dalam menganalisa kondisi eksternal adalah metode 4C Diamond.

Tabel 1.

Faktor Eksternal

\begin{tabular}{cc}
\hline \hline \multicolumn{2}{c}{ Faktor Eksternal } \\
\hline Peluang & Ancaman \\
\hline Cita - cita Indonesia sebagai & Tuntuan penerapan \\
poros martim melalui & teknologi yang semakin \\
program Tol Laut & canggih \\
Dukungan Pemerintah & Lemahnya nilai tukar \\
berupa azas cabotage & Rupiah \\
Pemberdayaan galangan & Lemahnya sektor \\
kapal nasional sesuai & permodalan dan \\
arahan langsung presiden & perbankan \\
PP No.69 Tahun 2015 & Terdapat 250 \\
Pembebasan atas Pungutan & galangan di \\
PPN angkutan tertentu & Indonesia \\
\hline \hline
\end{tabular}

\section{B. Analisa Kondisi Internal}

Pada penelitian ini analisis lingkungan internal dilakukan dengan menggunakan Business Model Canvas (BMC). BMC adalah sebuah model bisnis yang menggambarkan dasar pemikiran tentang bagaimana sebuah organisasi atau perusahaan menciptakan, menyerahkan, dan menangkap nilai 
Tabel 2

Faktor Internal

\begin{tabular}{cc}
\hline \hline \multicolumn{2}{c}{ Faktor Internal } \\
\hline Kekuatan & Kelemahan \\
\hline Memiliki Program & Perlengkapan produksi \\
Home Doctor Service & dengan umur cukup tua \\
Memiliki banyak & Lemahnya manajemen \\
partner bisnis & proyek: produktivitas \\
Fasilitas lengkap & Mengalami keterlambatan \\
Tenaga kerja berpengalaman & kerja \\
Brand Awareness tinggi & Material bergantung \\
di masyarakat & pada supplier \\
Memiliki lahan galangan & \\
di Lamongan & \\
\hline \hline
\end{tabular}

\section{Matriks EFAS}

Pada matriks External Factor Analysis Summary ini akan diketahui skor yang didapat dari pembobotan dan nilai rata rata penilaian untuk faktor eksternal. Nilai untuk tiap faktor adalah $1-5$. Pada kolom peluang, nilai 1 merupakan faktor yang tidak berpengaruh, sedangkan angka 5 adalah yang paling berpengaruh terhadap perusahaan. Sebaliknya, pada kolom ancaman, angka 1 merupakan yang paling berpengaruh, sedangkan angka 5 adalah yang tidak berpengaruh.

Tabel.3

Matriks EFAS

\begin{tabular}{|c|c|c|c|}
\hline Peluang & Bobot & Rata-rata & Skor \\
\hline $\begin{array}{l}\text { Cita - cita Indonesia sebagai } \\
\text { poros martim melalui } \\
\text { program Tol Laut }\end{array}$ & 0.17 & 3.8 & 0.646 \\
\hline $\begin{array}{l}\text { Dukungan Pemerintah } \\
\text { berupa azas cabotage }\end{array}$ & 0.17 & 3.3 & 0.561 \\
\hline $\begin{array}{l}\text { Pemberdayaan galangan } \\
\text { kapal nasional sesuai } \\
\text { arahan langsung presiden } \\
\text { PP No.69 Tahun } 2015\end{array}$ & 0.1 & 3.2 & 0.32 \\
\hline $\begin{array}{l}\text { Pembebasan atas Pungutan } \\
\text { PPN angkutan tertentu }\end{array}$ & 0.08 & 3.8 & 0.304 \\
\hline $\begin{array}{c}\text { Ancaman } \\
\text { Tuntuan penerapan }\end{array}$ & Bobot & Rata-rata & Skor \\
\hline $\begin{array}{l}\text { teknologi yang semakin } \\
\text { canggih }\end{array}$ & 0.17 & 2.4 & 0.408 \\
\hline $\begin{array}{c}\text { Lemahnya nilai tukar } \\
\text { Rupiah }\end{array}$ & 0.15 & 1.5 & 0.225 \\
\hline $\begin{array}{l}\text { Lemahnya sektor } \\
\text { permodalan dan } \\
\text { perbankan }\end{array}$ & 0.08 & 3.4 & 0.272 \\
\hline $\begin{array}{l}\text { Terdapat } 250 \\
\text { galangan di } \\
\text { Indonesia }\end{array}$ & 0.08 & 2.8 & 0.224 \\
\hline Total & & & 2.96 \\
\hline
\end{tabular}

\section{Matriks IFAS}

Pada matriks Internal Factor Analysis Summary akan didapat penilaian dari faktor - faktor internal yang merupakan kekuatan dan kelemahan perusahaan. Skor yang didapat adalah perkalian dari pembobotan dan nilai rata - rata dari setiap faktor. Nilai yang diberikan merupakan angka $1-5$. Untuk faktor kekuatan, angka 1 merupakan yang paling tidak berpengaruh, sedangkan angka 5 adalah yang paling berpenagaruh. Sebaliknya, untuk faktor ancaman angka 1 adalah yang berpengaruh, sedangkan angka 5 tidak.

Tabel. 4

Matriks IFAS

\begin{tabular}{|c|c|c|c|}
\hline Kelemahan & Bobot & Rata-rata & Skor \\
\hline $\begin{array}{l}\text { Perlengkapan produksi } \\
\text { dengan umur cukup tua }\end{array}$ & 0.075 & 1.7 & 0.1275 \\
\hline $\begin{array}{l}\text { Lemahnya manajemen } \\
\text { proyek: produktivitas }\end{array}$ & 0.08 & 2.9 & 0.232 \\
\hline $\begin{array}{c}\text { Mengalami keterlambatan } \\
\text { kerja }\end{array}$ & 0.075 & 1.9 & 0.1425 \\
\hline $\begin{array}{c}\text { Material bergantung } \\
\text { pada supplier }\end{array}$ & 0.08 & 1.3 & 0.104 \\
\hline Kekuatan & Bobot & Rata - rata & Skor \\
\hline $\begin{array}{c}\text { Memiliki Program } \\
\text { Home Doctor Service }\end{array}$ & 0.15 & 4 & 0.6 \\
\hline $\begin{array}{c}\text { Memiliki banyak } \\
\text { partner bisnis }\end{array}$ & 0.11 & 3 & 0.33 \\
\hline Fasilitas lengkap & 0.12 & 3.6 & 0.432 \\
\hline Tenaga kerja berpengalaman & 0.12 & 3.5 & 0.42 \\
\hline $\begin{array}{c}\text { Brand Awareness tinggi } \\
\text { di masyarakat }\end{array}$ & 0.095 & 3.1 & 0.2945 \\
\hline $\begin{array}{c}\text { Memiliki lahan galangan } \\
\text { di Lamongan }\end{array}$ & 0.095 & 3.1 & 0.2945 \\
\hline Total & & & 2.977 \\
\hline
\end{tabular}

\section{E. Matriks IE}

Matriks IE berfungsi untuk mengetahui keadaan perusahaan sesuai kondisi saat ini. Keadaannya dapat diketahui dari skor yang didapatkan dari faktor eksternal dan internal.

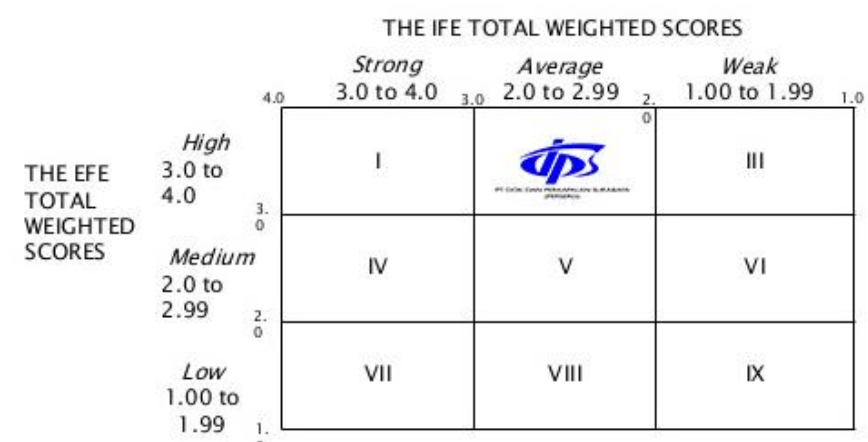

Gambar 1. Matriks IE

Dari Matriks dapat diketaui posisi perusahaan berada pada kuadran II. Kondisi perusahaan pada kuadran ini adalah Grow and Build. Tema strategi pada keadaan ini adalah integrasi horizontal. Kegiatan ini merupakan suatu cara untuk membangun perusahaan melalui pembangunan di lokasi lain atau meningkatkan jenis produk dan jasa. Tujuannya adalah untuk meningkatkan penjualan dan profit, dengan cara memanfaatkan keuntungan economics of scale baik dalam produksi maupun pemasaran. Perusahaan pada kuadran ini dapat memperluas pasar, fasilitas produksi, dan teknologi 
melalui pengembangan internal maupun eksternal melalui akuisisi atau joint venture dengan perusahaan lain dalam industri yang sama.

\section{F. Matriks TOWS}

Matriks TOWS ini akan menghasilkan berbagai macam strategi yang sesuai dengan tema strategi sebelumnya, yaitu integrasi horizontal. Berikut adalah strategi yang dapat disimpulkan:

\section{Strategi SO}

a. Mengoptimalkan program Home Doctor Service pada konsumen.

b. Menyegerakan pengembangan galangan di Lamongan

2. Strategi ST

a. Meningkatkan kwalitas dan brand awareness yang telah dimiliki

b. Membuat penawaran menarik dari resourches dan partnership yang perusahaan miliki

\section{Strategi WO}

a. Meningkatkan daya saing melalui persaingan biaya produksi

b. Meningkatkan kinerja manajemen

4. Strategi WT

a. Kerjasama antar galangan

b. Perawatan fasilitas akibat tuntutan perkembangan jaman

\section{G. Analytical Hierarchy Process (AHP)}

Metode AHP ini yang akan membantu untuk menentukan strategi mana yang paling dapat digunakan untuk kondisi perusahaan saat ini.

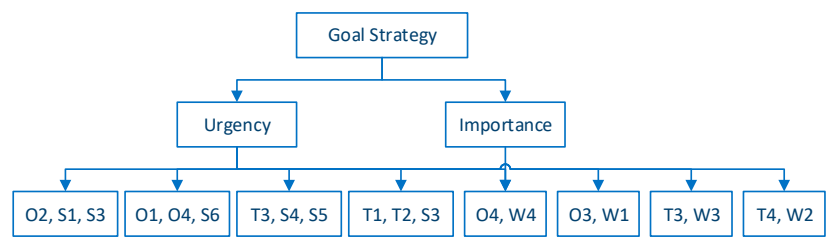

Gambar 2. Pohon Strategi

Terdapat dua kriteria untuk mempengaruhi tujuan secara langsung. Seperti pada macam strategi yang telah dihasilkan sebelumnya, terdapat delapan strategi untuk mempengaruhi kriteria dan secara langsung mempengaruhi pula tujuannya.

Dari hasil rata-rata didapatkan nilai dominan kriteria urgency. Maka dibuat matriks berikut :

Tabel. 5

Matriks kriteria

\begin{tabular}{ccc}
\multicolumn{3}{c}{ Matriks kriteria } \\
\hline \hline kriteria & urgency & importance \\
\hline urgency & 1 & 2 \\
importance & $1 / 2$ & 1 \\
\hline \hline
\end{tabular}

Setelah dilakukan perhitungan bobot dari matriks kriteria didapatkan nilai untuk kriteria urgency adalah 0,667 dan untuk kriteria importance adalah 0,333. Setelah itu dibuat matriks untuk penilaian tiap alternatif. Berikut adalah matriks alterantif untuk kriteria urgency.
Tabel 6

Matriks AHP kriteria urgency

\begin{tabular}{ccccccccc}
\hline \hline & SO a & SO b & ST a & ST b & WO a & WO b & WT a & WT b \\
\hline SO a & 1.00 & 5.00 & 2.00 & 0.50 & 0.50 & 0.33 & 1.00 & 0.33 \\
SO b & 0.20 & 1.00 & 0.33 & 0.33 & 0.50 & 0.33 & 1.00 & 0.50 \\
ST a & 0.50 & 3.00 & 1.00 & 1.00 & 0.33 & 1.00 & 3.00 & 0.50 \\
ST b & 2.00 & 3.00 & 1.00 & 1.00 & 1.00 & 2.00 & 2.00 & 1.00 \\
WO a & 2.00 & 2.00 & 3.00 & 1.00 & 1.00 & 0.50 & 3.00 & 0.50 \\
WO b & 3.00 & 3.00 & 1.00 & 1.00 & 2.00 & 1.00 & 3.00 & 1.00 \\
WT a & 1.00 & 1.00 & 0.33 & 0.50 & 0.33 & 0.33 & 1.00 & 0.33 \\
WT b & 3.00 & 2.00 & 2.00 & 1.00 & 2.00 & 1.00 & 3.00 & 1.00 \\
\hline \hline
\end{tabular}

Setelah dinormalisasi dan dihitung nilai consistency ratio didapatkan angka 0,09. Apabila nilai CR dibawah 0,1 maka matriks dianggap telah konsisten. Lalu dihitung juga untuk alternatif kriteria importance dengan cara yang sama seperti sebelumnya.

Tabel. 7

Matriks AHP kriteria importance

\begin{tabular}{ccccccccc}
\hline \hline & SO a & SO b & ST a & ST b & WO a & WO b & WT a & WT b \\
\hline SO a & 1.0 & 5.0 & 0.50 & 0.50 & 0.5 & 0.2 & 1.0 & 0.3 \\
SO b & 0.2 & 1.0 & 0.33 & 0.33 & 0.5 & 0.3 & 1.0 & 0.5 \\
ST a & 2.0 & 3.0 & 1.00 & 1.00 & 0.3 & 1.0 & 3.0 & 3.0 \\
ST b & 2.0 & 3.0 & 1.00 & 1.00 & 1.0 & 2.0 & 2.0 & 1.0 \\
WO a & 2.0 & 2.0 & 3.00 & 1.00 & 1.0 & 1.0 & 3.0 & 0.5 \\
WO b & 5.0 & 3.0 & 1.00 & 1.00 & 1.0 & 1.0 & 4.0 & 1.0 \\
WT a & 1.0 & 1.0 & 0.33 & 0.50 & 0.3 & 0.25 & 1.0 & 0.3 \\
WT b & 3.0 & 2.0 & 0.33 & 1.00 & 2.0 & 1.0 & 3.0 & 1.0 \\
\hline \hline
\end{tabular}

Setelah dinormalisasi dan dihitung nilai consistency ratio didapatkan angka 0,08. Apabila nilai CR dibawah 0,1 maka matriks dianggap telah konsisten. Dengan software perhitungan numerik untuk pengambil keputusan didapatkan angka validasi dari perhitungan manual yang telah dilakukan.

Tabel. 8

Perbandingan perhitungan manual dan software

\begin{tabular}{cccc}
\hline \hline & hasil & hasil & \multirow{2}{*}{ koreksi \% } \\
\cline { 2 - 3 } alternatif & manual & software & \\
\hline SO a & 0.0897 & 0.088 & $0.17 \%$ \\
So b & 0.0512 & 0.05 & $0.12 \%$ \\
ST a & 0.1481 & 0.15 & $0.19 \%$ \\
ST b & 0.1587 & 0.16 & $0.13 \%$ \\
WO a & 0.1583 & 0.163 & $0.47 \%$ \\
WO b & 0.1759 & 0.17 & $0.59 \%$ \\
WT a & 0.054 & 0.054 & $0.00 \%$ \\
WT b & 0.1636 & 0.165 & $0.14 \%$ \\
\hline \hline
\end{tabular}


Didapatkan nilai koreksi yang kecil untuk tiap alternatif, maka perhitungan manual dianggap benar.

\section{KESIMPULAN}

Dari hasil analisis eskternal (4C Diamond Analysis) dan internal (Business Model Canvas) didapatkan faktor - faktor yang mempengaruhi pengembangan perusahaan ini. Faktor faktornya adalah sebagai berikut:

\section{A. Faktor Eksternal}

- Lemahnya nilai tukar rupiah

- Lemahnya sektor permodalan

- Tuntutan penerapan teknologi yang pesat

- Terdapat 250 galangan di Indonesia

- Cita - cita Indonesia sebagai poros maritime melalui program tol laut : diperlukan mencapai 150 unit kapal baru hingga 2019

- Dukungan pemerintah berupa azas cabotage

- Dukungan pemerintah untuk memberdayakan galangan kapal nasional : proyek oil tanker 3500, 6500, 13.000 DWT

- Pembebasan atas pungutan PPN jasa angkut tertentu (PP No. 69 Tahun 2015)

\section{B. Faktor Internal}

- Lemahnya manajemen proyek : produktivitas perusahaan masih dibawah standar

- Perlengkapan produksi dengan umur cukup tua

- Mengalami keterlambatan kerja

- Material bergantung pada supplier

- Memiliki program Home Doctor Service

- Memiliki banyak partner bisnis

- Memiliki fasilitas lengkap

- Tenaga kerja berpengalaman

- Brand awareness tinggi di masyarakat

- Mengembangkan galangan di Lamongan

Perusahaan berada pada kondisi grow and build. Tema strategi yang dapat digunakan adalah integrasi horizontal. Didaptkan delapan strategi untuk mengembangkan perusahaan. setelah dilakukan perhitungan menggunakan metode AHP didapatkan satu strategi yang dapat digunakan perusahaan untuk kondisi saat ini yaitu WO b.

Hasil strategi tertinggi adalah persilangan dari dukungan pemerintah untuk memberdayakan galangan nasional dengan rendahnya kinerja manajemen perusahaan seperti angka produktivitas yang masih dibawah standar yang perusahaan tetapkan. Strateginya adalah meningkatkan kinerjanya dengan membuat evaluasi tiap pekerjaan dan dibagi lagi dengan membuat evaluasi tiap jenis pekerkaan (job order). Agar dapat diketahui jenis kegiatan yang mana yang memiliki produktivitas paling rendah. Karena dengan adanya dukungan pemerintah terhadap galangan nasional akan membuka peluang baru bagi perusahaan untuk mendapatkan lebih banyak permintaan (demands), maka dari itu harus diimbangi dengan produktivitas yang perlu ditingkatkan pula.

\section{UCAPAN TERIMA KASIH}

Penulis mengucapkan terima kasih kepada seluruh civitas akademika Departemen Teknik Kelautan ITS, karyawan PT. Dok dan Perkapalan Surabaya, seluruh teman dekat penulis atas semangat dan bantuan yang diberikan.

\section{DAFTAR PUSTAKA}

[1] (Monograph Online Sources) B.C. Arum, "Jadi Sektor Strategis, Pemerintah Tingkatkan Perhatian Pada Industri Galangan Kapal," $2017 . \quad$ [Online]. Available: http://industri.bisnis.com/read/20170326/98/640395/jadi-sektorstrategis-pemerintah-tingkatkan-perhatian-pada-industri-galangankapal.

[2] (Monograph Online Sources) A.N.T., "Bea Masuk dihapus, Pengusaha Kita Butuh Kepastian Pembangunan Kapal,” 2017. [Online]. Available: https://economy.okezone.com/read/2017/06/20/320/1720723/beamasuk-dihapus-pengusaha-kita-butuh-kepastian-pembangunan-kapal.

[3] (Monograph Online Sources) S.N.Azzura, "Bos PT PAL Harap Sinergi BUMN Beri Nilai Tambag Industri Perkapalan RI," 2017. [Online]. Available: https://www.merdeka.com/uang/bos-pt-pal-harap-sinergibumn-beri-nilai-tambah-industri-perkapalan-ri.html.

[4] (Monograph Online Sources) I. Wahyudiyanta, "Dapat Suntikan Dana Rp 200 M, BUMN ini Fokus jadi ‘Bengkel' Kapal,” 2016. [Online]. Available: https://finance.detik.com/berita-ekonomibisnis/3201990/dapat-suntikan-rp-200-m-bumn-ini-fokus-jadibengkel-kapal.

[5] (Monograph Online Sources) R. Maulana, "Dok Perkapalan Surabaya Dapat Pesanan 3 Kapal Senilai U\$ 21 Juta," 2017. [Online]. Available: http://industri.bisnis.com/read/20170929/98/694289/dok-perkapalansurabaya-dapat-pesanan-3-kapal-senilai-us21-juta.

[6] (Monograph Online Sources) S.N.Azzura, "Dua Perusahaan BUMN Bidang Galangan Masih Merugi," 2017. [Online]. Available: https://www.merdeka.com/uang/dua-perusahaan-bumn-bidanggalangan-kapal-masih-merugi.html.

[7] A. B. Prakoso, "Analisa Strategi Pemasaran Produk Kosmetik Wardah dengan Pendekatan SWOT-AHP (Analytic Hierarchy Process)," ITS, 2017.

[8] R. Sudaryanto, "Integrasi Threats Opportunities Weakness Strength (TOWS), Analythica Hierarchy Process (AHP) dan Simple Additive Weighting (SAW) dalam Perumusan Strategi (Studi Kasus PT. XYZ)," 2001.

[9] A. Wurdianto, "Perancangan Strategi Pengembangan Usaha pada Divisi Rekayasa Umum, di PT XYZ,” ITS, 2017. 